\title{
COMMENT
}

\section{Destruction of chloropigments in copepod guts}

\author{
A. B. Bochdansky*, D. Deibel \\ Ocean Sciences Centre, Memorial University of Newfoundland, St. John's, Newfoundland, Canada A1C 5S7
}

In a recent account regarding the destruction of chloropigments within the guts of copepods, Head \& Harris (1996) (H\&H) presented valuable data on pigment destruction in copepods. However, in one of their main conclusions, the authors invoked 2 enzyme pools to explain the pattern of pigment destruction: one directly derived from copepods, the other one produced by the ingested algae. If this conclusion is correct, it would have tremendous impact on the interpretation of data collected by the gut pigment technique. Estimating ingestion rates of copepods in the field would be very difficult, if not impossible, if pigment destruction was dependent upon an unknown food composition in the gut. We therefore felt it necessary to examine the evidence presented in $\mathrm{H} \& \mathrm{H}$ carefully. As we will demonstrate, (1) there is no evidence to postulate the existence of 2 enzyme pools, and (2) the majority of enzymes responsible for pigment destruction are as likely to originate from copepods as from the ingested algae.

We scanned Fig. $4 \mathrm{~b}$ of H\&H with a HP Scanjet IIC color scanner and digitized the data with the image analysis software 'Data Thief' (by Kees Huyser and Jan van der Laan, National Institute for Nuclear Physics and High Energy Physics, Amsterdam, The Netherlands). We did not directly use the data shown in Fig. 7 of $\mathrm{H} \& \mathrm{H}$ because the data in Fig. 4 had fewer hidden points and could therefore be reproduced more accurately. Fig. 7 was constructed by $\mathrm{H} \& H$ by multiplying the proportion of pigment destruction by the ingestion rate. Of 102 data points used in Fig. 4 of $\mathrm{H} \& \mathrm{H}$, only 80 points were visible. However, when calculating the linear regression through these 80 data points, the estimated parameters as well as the calculated coefficient of determination were very similar to the original (Fig. 1a).

\footnotetext{
·E-mail: bochdan@morgan.ucs.mun.ca
}

H\&H estimated enzyme activity by multiplying chlorophyll destruction ( $y$-axis) by ingestion rate ( $x$ axis), and then plotted enzyme activity versus ingestion rate creating an autocorrelation in Fig. 7. Instead of using the percentage value, $\mathrm{H} \& \mathrm{H}$ multiplied the $x$ axis from Fig. 4 by the proportion of chlorophyll destruction ranging from ca 0.45 to 1 . Hence, the units of the $x$-and $y$-axes of Fig. 7 are identical (ng $\mathrm{mg} \mathrm{h}^{-1}$ ). Due to this autocorrelation, one would expect a linear relationship to result from any random distribution of a $y$-variate multiplied by an $x$-variate and plotted against the $x$-variate. However, as is already apparent from Fig. 4, the relationship is not exactly linear, but slightly curved. The curve begins with a slope of ca 1 at low ingestion rates (i.e. $100 \%$ chlorophyll destruction) and decreases to ca 0.45 (i.e. $45 \%$ chlorophyll destruction) since the proportion of pigment destruction is decreasing with increasing ingestion rates. Another consequence of the autocorrelated data set is that there cannot be an intercept, since any product of 0 equals 0 . Since ingestion rate is multiplied by chlorophyll destruction to calculate enzyme activity, the product is 0 whenever ingestion rate equals 0 . Instead, the positive intercept in $\mathrm{H} \& \mathrm{H}$ is an artifact caused by data points in the upper part of the curve which 'drive' the linear regression, a common problem in regression analysis (i.e. outliers have more influence on the regression line and rotate the line around the mean). It is therefore no coincidence that the slope of the linear regression (Fig. 7) and the proportion of enzyme destruction at high ingestion rates (Fig. 4) are almost identical (i.e. approximately 0.45).

In using a linear regression for displaying enzyme kinetics, $\mathrm{H} \& \mathrm{H}$ chose an unconventional approach. In the simplest enzyme-substrate relationship, one would expect the kinetics to follow the classic MichaelisMenten model (Michaelis \& Menten 1913) and not a straight line. In this model of regulation of enzyme 

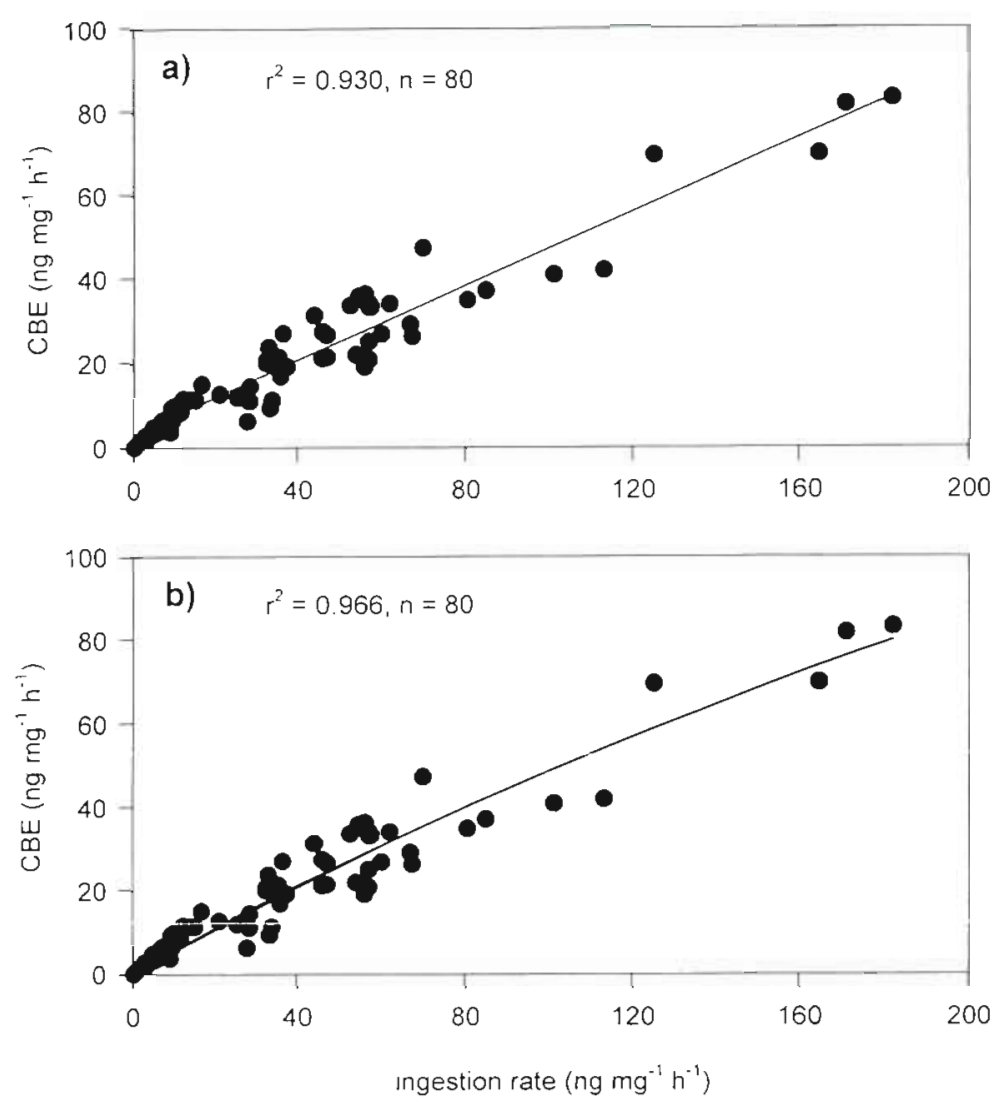

Fig. 1. Comparison of the linear regression as presented by Head \& Harris (1996) (a) and the Michaelis-Menten saturation equation for substrate-regulated enzyme kinetic for the same data set (b). CBE: chlorophyll bleaching enzyme activity; IR: ingestion rate, which was used by $\mathrm{H} \& \mathrm{H}$ as a proxy for substrate concentration. For comparison, the equation of the original regression in $\mathrm{H} \& \mathrm{H}$ is: $\mathrm{CBE}=2.64+0.45 \mathrm{IR}$. The parameters of the Michaelis-Menten equation in (b) are only applicable within the range of the observations, since no information on the saturated part of the curve exists. $X$-and $y$-axes were drawn to scale as in $H \& H$. The equations for the models are: for (a), $C B E=3.15+0.44 I R$, and for (b), $\mathrm{CBE}=355 \mathrm{IR} /(626+\mathrm{IR})$

activity, the rate of substrate conversion is limited by the amount of substrate available. The maximum potential enzyme activity occurs when saturation with the substrate is reached $\left(v_{\max }\right)$. Since substrate availability in the gut of animals is presumably directly proportional to ingestion rate, $\mathrm{H} \& \mathrm{H}$ replaced substrate concentration by ingestion rate. Following this logic, the Michaelis-Menten equation can be written as:

$$
\mathrm{CBE}=v_{\max } \cdot \mathrm{IR} /\left(K_{\mathrm{m}}+\mathrm{IR}\right)
$$

where CBE is the enzyme activity of the 'chlorophyll bleaching enzyme' (from $H \& H$ ), IR the ingestion rate, $v_{\max }$ the maximum enzyme activity at saturation and $K_{\mathrm{m}}$ the half-saturation constant. For estimation of the parameters $v_{\max }$ and $K_{\mathrm{m}}$, the most frequently used linear transform is the Lineweaver-Burk transformation or double reciprocal method (Lineweaver \& Burk
1934). However, this transformation can only be applied in cases where the data follow the saturation curve precisely and where small values can be determined with highest accuracy since they have great influence on the regression analysis (Dowd \& Riggs 1965). Since the H\&H data were considerably scattered as is typical for zooplankton feeding studies, a nonlinear curvefit using the Marquardt-Levenberg algorithm is preferred (Berges et al. 1994). As Fig. 1 shows, a curve fits the data at least as well as the linear regression of $\mathrm{H} \& \mathrm{H}\left(\mathrm{r}^{2}=0.966\right)$, and the intercept equals 0 after fitting a curve. The crude estimate of the $v_{\max }$ value suggests that the enzymes in the copepods are capable of destroying much more chloropigment than was available and that saturation was not reached. This conclusion is in opposition to that of $\mathrm{H} \& \mathrm{H}$. Instead of only a small enzyme activity of $2.64 \mathrm{ng} \mathrm{mg}^{-1} \mathrm{~h}^{-1}$ (corresponding to the $y$-intercept in $\mathrm{H} \& \mathrm{H}_{\text {; Fig. }}$ ) which was dssigned io the copepods i.e. oniy $3.3 \%$ of the maximum enzyme activity attributed to the algae), the maximum potential enzyme activity of the copepods would be much higher and outside the range of the experimental data. (Fig. 1b).

We are aware of the problem of extrapolating the given data beyond the range of the observations, since no data for the 'saturated part' of the curve or even covering the range of the half saturation constant of the curve exist. Since maximum ingestion rates in this example seem to be high, it is also possible that enzyme saturation is never reached, even in a full copepod gut. The estimated parameters from our analysis therefore refer only to the range of the original observations, and show that a plausible, simple and mathematically consistent explanation for the observed enzyme kinetics of the 'chlorophyll bleaching enzyme' exists without invoking the presence of an additional enzyme pool. H\&H have therefore not rejected the null hypothesis that all of the enzymes responsible for pigment destruction derive from copepods.

Acknowledgements. We thank Drs R. J. Thompson and R. B. Rivkin for valuable comments on an earlier draft of this manuscript.

\section{LITERATURE CITED}

Berges JA, Montagnes DJS, Hurd CL, Harrison PJ (1994) Fitting ecological and physiological data to rectangular hyperbolae: a comparison of methods using Monte Carlo 
simulations. Mar Ecol Prog Ser 114:175-183

Dowd JE, Riggs DS (1965) A comparison of estimates of Michaelis-Menten kinetic constants from various linear transformations. J Biol Chem 240:863-869

Head EJH, Harris LR (1996) Chlorophyll destruction by Calanus spp. grazing on phytoplankton: kinetics, effects of ingestion rate and feeding history, and a mechanistic interpretation. Mar Ecol Prog Ser 135:223-235

Lineweaver H, Burk D (1934) The determination of enzyme dissociation constants. J Am Chem Soc 56:658-666

Michaelis L, Menten ML (1913) Die Kinetik der Invertinwirkung. Biochem Z 49:333-369 